\title{
"ANA" E "ELIANA": Relações Interétnicas entre uma cigana do Clã Calon e uma brasileira evangélica na cidade de Jequié-Ba ${ }^{1}$
}

\author{
Silvany Ferreira da Silva ${ }^{2}$ \\ Programa de Pós-Graduação em Relações Étnicas e Contemporaneidade \\ Washington Santos Nascimento 3 (i) \\ Universidade do Estado do Rio de Janeiro \\ Natalino Perovano Filho 4 (iD) \\ Universidade Estadual do Sudoeste da Bahia
}

Artigos livres | Free articles | Articulos libres

DOI do artigo: 10.22481/odeere.v6i2.9817

RESUMO

Esta pesquisa tem como temática as relações Interétnicas entre uma cigana Calon e uma brasileira evangélica na cidade de Jequié-Ba. Para a coleta dos dados utilizamos o método etnográfico. Como técnica de investigação utilizamos a observação participante de contato direto da pesquisadora com a pesquisadas e entrevistas semiestruturadas e o apoio do diário de campo.

Palavras chave: Relações Étnicas. Cigana. Calon. Brasileira.

\section{ANA" AND "ELIANA": Interethnic relations between a Gypsy from the Clan Calon and a Brazilian evangelical in the city of Jequié-Ba \\ ABSTRACT}

This research is thematic. "Ana and Eliana": Ethnic Relations between a Gypsy and a Brazilian evangelical in the city of Jequié-Ba. For data collection we used the ethnographic method, as a research technique we used participant observation of direct contact between the researcher and the researched and semi-structured interviews and the support of the field diary.

Keywords: Ethnic Relations. Gipsy. Calon. Brazilian.

\section{ANA" Y "ELIANA": Relaciones interétnicos entre un gitano del Clan Calon y un brasileño evangélico en la ciudad de Jequié-Ba}

\section{RESUMEN}

Esta investigación es temática. "Ana y Eliana": Relaciones étnicas entre un gitano y un brasileño evangélico en la ciudad de Jequié-Ba. Para la recolección de datos utilizamos el método etnográfico, como técnica de investigación utilizó la observación participante del contacto directo entre el investigador y el investigado y entrevistas semiestructuradas y el apoyo del diario de campo. Palabras clave: Relaciones étnicas. Gitana. Calon. Brasileña.

\section{Submetido em: $01 / 11 / 2021$ | Aceito em: 24/12/2021}

\section{INTRODUÇÃO}

Para iniciarmos a nossa investigação sobre as bases das identidades de uma mulher cigana e a outra uma brasileira, faz-se necessário contextualizarmos as duas

\footnotetext{
1 Resultados parciais da pesquisa de mestrado Silvany Ferreira da Silva desenvolvida por tendo como ORIENTADOR: Prof. Dr. Washington Santos Nascimento e COORIENTADOR: Prof. Dr. Natalino Perovano Filho.

2 Bacharel em Serviço Social (UNOPAR). Especialista em Serviço Social e Política Pública (FAVIC), através do (CEEPEV). Mestranda em Relações Étnicas e contemporaneidade com pesquisa sobre os ciganos em Jequié -BA. E-mail: silvany_ferreiral@hotmail.com

3 Professor da Universidade do Estado do Rio de Janeiro (UERJ). Professor do Programa de PósGraduação em Relações Étnicas e Contemporâneidade - UESB. E-mail: washingtonprof@gmail.com 4 Doutorado em 2016 (UESC), Docente permanente do Programa de Pós-Graduação em Relações Étnicas e Contemporaneidade, e-mail: npfilho@vesb.edu.br
} 
informantes da pesquisa. Conforme Moonen (2011) "O Calon ou Kalé foram um dos primeiros ciganos a entrar no Brasil, originário da Península Ibérica no século XVI". Vale sinalizar que o termo Calon, faz referência do mesmo modo, a homem cigano. Dialogando ainda com esse conceito é importante destacar que existem mais dois grupos que se identificam como Calón, os Rom e Sinti, que se estabeleceram também no Brasil.

As interlocutoras sociais desta pesquisa, uma cigana do clã Calon, e uma brasileira, são habitantes do município de Jequié-Ba, com idades entre 28 a 67 anos. Sendo que a primeira a cigana "Ana" (nome fictício) grande parte dos seus relatos nos foram dados no acampamento e a brasileira "Eliana" (nome fictício) em sua residência.

\section{A HISTÓRIA DE ANA, PRIMEIRA PARTICIPANTE DA PESQUISA}

Em uma quinta-feira, à noite, do dia 02 do mês de maio de 2019, ao retirarse de um restaurante com amigos do Curso de Línguas Modernas da Universidade Oxford, notamos algumas ciganas no centro do município de Jequié- Ba, sentadas no banco da praça, dialogando entre si em voz alta, sobre a discriminação que passaram pelo fato de serem ciganas, acontecimento este corriqueiro desde os primórdios.

Diante do episódio apreciado, aproximei-me das Calins, nome utilizados para meninas, mulheres ciganas da etnia Calon. Exclamei: que ciganas lindas! Uma das moças respondeu: obrigada. Começamos a conversar. A princípio, desenvolvemos uma conversa informal sobre seus vestidos.

Imediatamente, indaguei se habitavam em Jequié, uma disse que sim, as outras que não, informaram que residiam em Wenceslau Guimarães, pronunciei meu nome, elas proferiram os delas, apresentei-me como estudante, que gostaria de conhecer a história cigana, se em outro momento teria a oportunidade de realizar uma entrevista com horário e data marcada, afirmaram que podia.

No mesmo instante, pedi 0 endereço que imediatamente registrei. Surpreendentemente, chegou o cônjuge de uma das mulheres, questionou o que eu desejava, a Calin, em alto contínuo, respondeu, a moça busca saber da história cigana, como a gente vive, a partir desse momento, se deu o primeiro contato inicial de forma precisa, objetiva, e uma despedida com até breve. 
Em seguida, ao afastar-se das Calins, detalhei no bloco de anotações como estava vestida a nossa partícipe Ana. Ela apresentou-se com o porte físico esguio, encontrava-se com uma blusa de botão frontal azul escuro, saia plissada lisa da cor preta, cabelo preto curto, havaianas, não usava maquiagem. As outras ciganas, uma usava vestidos de renda verde claro, havaianas, no cabelo coque e pente, a outra com vestido de renda branco com lantejoulas, havaianas, no cabelo pirote, pente, dente de ouro, brincos grandes e maquiagem suave.

Após descrever os vestidos utilizados pelas primas da Calin, que não vão fazer parte da pesquisa, suas faces não foram apresentadas como também seus nomes, pois as ciganas pediram sigilo, mas, decidiram apresentar os vestidos lindíssimos e sua simbologia que representam suas tradições e por isso, foram expostos.

Como se vê na imagem a baixo colocamos algumas fotografias que representam um dos aspectos mais importante de sua cultura para as mulheres ciganas e para o grupo, pois os significados da veste e detalhes dentro da tradição têm diversas interpretações, sendo assim, para entender a cultura cigana é necessário conhecer a simbologia das cores, devido evidenciar o lado místico da cultura.

Como mostra a Figura 01 as rendas utilizadas, as lantejoulas, as cores as camadas godês representam também a resistências dos valores de seus ancestrais, bem como, observamos que desde o século XVI são mantidas o mesmo estilo de vestimentas marcando assim os seus valores.

Diante disso consideramos a importância de evidenciarmos na pesquisa as vestimentas das mulheres ciganas (Fig. 01), por fazer parte dos sinais diacríticos da cultura e por ser um processo de afirmação ética, além de que também é fundamental para ressignificar a vivência e compreender a cultura.

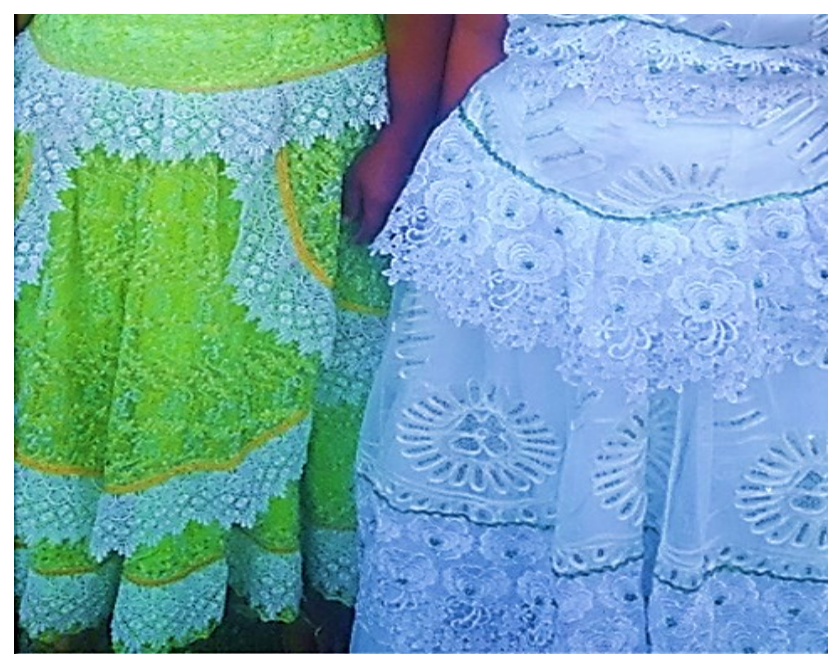

FIGURA 01 - Vestidos das mulheres Calon. Fonte: Acervo pessoal de Silvany Ferreira da Silva. 
Em continuação as conversas informais as Calins, me informaram que as vestes ciganas trazem expressões identitárias simbólicas, e o colorido e adornos, adquirem para as Calin, equilíbrio e a cura de muitos males do corpo, alma, ao mesmo tempo, incorporam adereços para se tornar cada vez mais belas inspirando o espírito e trazer boas novidades.

Grossmann (2018) em sua Tese de Doutorado, menciona que, "a vestimenta cigana possui camadas de significados que incluí desde a escolha do comprimento da veste, do comprimento do pano, das camadas gôdes da saia ou do vestido, bem como da importância e simbologia das cores empregada".

Sobre o ponto de vista da depoente, as cores representadas em seus vestidos (Quadro 01), simbolizam a vida e alegria, sendo que as cores brancas ao ser utilizadas trazem uma sensação de paz, e tranquilidade espiritual, discernimento no campo material e relaxamento mental. A cor verde é boa para a saúde, coração, para o lado sentimental, traz esperança, harmonia, confiança e disposição para viver, logo, os mesmos devem ser usados quando queremos recuperar o nosso vigor.

QUADRO 01. Cores das simbologias dos vestidos ciganos:

\begin{tabular}{|c|c|}
\hline CORES & SIMBOLOGIAS \\
\hline BRANCA & TRANQUILIDADE ESPIRITUAL, RELAXAMENTO MENTAL \\
\hline AMARELO & CORAGEM AUTOCONFIANÇA \\
\hline AZUL CLARO & SENSIBILIDADE \\
\hline AZUL ESCURO & CONFIANÇA, DISCIPLINA \\
\hline LILÁS & PANTASIAS \\
\hline VIOLETA & SAÚDE, DISPOSIÇÃO PARA VIVER \\
\hline VERDE & SUAVIDADE \\
\hline ROSA & LIBERDADE, ENTUSIASMO, PRAZER DE ESTAR VIVO \\
\hline LARANJA & PAIXÃO, SEDUÇÃO \\
\hline VERMELHO &
\end{tabular}

É interessante percebermos nestas informações que as vestimentas são elementos diacríticos de reconhecimento e sinalização do pertencimento dos grupos das mulheres Calins, portanto quando reconhecidas pelos outros transmitem status, gostos e sociabilidades, além de respeito a sua própria cultura.

As Calins, usam todos os tipos de cores em suas indumentárias e adereços devido a liberdade ser o colorido da vida. Além do mais, cada cor tem funções 
diferenciadas. Em virtude dessas observações, podemos assegurar que as roupas são traços identitários fortes da cultura cigana, em função dos elementos culturais étnicos estarem presente como um cartão de visitas de um povo, por mostrar seu alinhamento com a cultura. É notório que, um traje carrega em si simbologias, sentimentos e o bel-prazer de quem à veste de diferentes formas, já que nossos olhares têm grande influência na imagem que analisamos e conhecimentos a respeito do mundo e das pessoas. Shimura, informa que:

o vestuário tradicional da mulher cigana conhecidos como "urdipens", saias e vestidos das ciganas Calins [...] possui um cânone de longa duração e alinha-se como um entendimento ligado à questão de marimé, ou vergonha cigana". (SHIMURA, 2017, p .189)

Peripolli (2013), ao estudar a mulher Calin a questão dos seus adornos diz que "o fato de ganhar uma maior quantidade de joias traz consigo, além do respeito, uma boa qualidade de vida oferecida por seu marido". A mulher Calin, muitas das vezes embelezam-se com ouro e prata para representar as riquezas de suas famílias em seus corpos, além de que, os adornos simbolizam a prosperidades.

Ainda, sobre as vestimentas ciganas é de bom tom clarificar as diferenças, para as mais jovens e as casadas foram observados que representam o recato, no entanto, para as casadas são ideais as saias longas e os vestidos devido significar o respeito ao marido, a família, grupo, a roupa também tem a ver com a moral e, verifica-se que não utilizam vestes que mostrem o corpo para não escandalizar o marido, a família e o grupo. As moças utilizam vestidos que podem variar os tecidos das saias sedo que poderão as mesmas ser saias retas e lisas, mas compridas.

Monteiro (1999), em seu estudo a metalinguagem das roupas traz a importância dos significados que as roupas carregam para a construção da identidade. A roupa sempre representa uma personalidade, de tal modo, as pessoas podem apresentar uma divergência das outras em relação ao que usa, além de que, com um tempo trouxe representações de classe, de casta social. É como se a pessoa afirmasse eu pertenço à determinada classe.

Reportando as afirmações de Shimura, Peripolli, Monteiro, nos faz pensar os ciganos como grupos diferentes entre si, e que ao mesmo tempo, ocupam lugares diferentes na sociedade que são demarcados através traços individuais entre os seus trajes e os papéis desenvolvidos na coletividade marcando assim a construção da identidade. 
A principal Calin, que na fase da pesquisa tivemos contato na zona urbana na cidade de Jequié-Ba, que me acolhev educadamente no campo, foi a senhora "Ana", líder do clã Calon. Por meio dela, procuramos conhecer suas histórias de vida, suas experiências, nos dias e horários marcados. Atendendo a questão ética antes de começar a entrevista, foi apresentar todas as informações relacionadas ao Termo de Consentimento Livre e Esclarecido (TCLE) da Comissão de Ética da Universidade Estadual do Sudoeste da Bahia, que possibilitaram alternativas para manter o sigilo, ou não, em relação ao nome social, que nesta pesquisa consiste em nome simulado Ana, para a mulher cigana, e Eliana, para a segunda entrevistada que de modo igual, optou por nome fictício.

Em primeiro lugar, apresentaremos de forma específica a história da líder Ana, a única do clã Calon, que participará da pesquisa por ter facilidades de comunicação na esfera social com os brasileiros. Uma vez que, conforme ela, em seu grupo, este lugar é permitido só a ela, por ser guardiã da sabedoria, tem o papel de observar a dinâmica das pessoas em seu grupo, seus comportamentos, as queixas, formas de comunicações e os papéis de lideranças disponibilizados para cada indivíduo, tanto coletivo como individual, bem como, providências relacionadas a assistência para a comunidade, alimentação, remédios, e proteção da comunidade diante de ameaças externas.

Ainda em sua narração a Calin, confirma que é líder e chefa do grupo, pois influenciam as gerações a valorizar o papel da chefa (autoridade local) e de um líder no grupo para não sofram punições. Por outro lado, como mãe, é idosa, é um dever ser respeitada pelos filhos e sempre ela que dá a última palavra, por esse motivo, no acampamento por questões culturais, obrigatoriamente as escolhidas são do sexo feminino e mais velhas do grupo. Perpétuo, em seu estudo assinala que "os mais velhos passam a cultura para as crianças, ao pé do ouvido, pela oralidade, de boca a boca, de geração em geração (PERPÉTUO, 2017, p.135) ".

Apesar das comunidades ciganas ser patriarcais em sua maioria, a participante Ana, diz que alguns acampamentos são liderados por mulheres, como em seu caso que constituiu o desejo do seu esposo antes do falecimento, ato comum em acampamentos brasileiros. Ventura (2004), relata que a relação de autoridade em família cigana se abanca na hierarquia de gênero e a idade como aspecto valorizado.

Em virtude da questão de gênero, outro fator de muita relevância é a 
palavra para um cigano ou Calin é sinal de honra, são como um documento, um contrato, é uma das maiores características de valor de sua etnia, pois uma palavra não cumprida de uma norma é uma falta grave.

A partir deste momento aconteceram as primeiras conversas em campo, estabelecemos um bate-papo aberto, com respeito e ética, para que fosse possível firmarmos uma relação de confiança e entrosamento entre as partes, tal quanto, não poderíamos deixar de falar que é significativo romper com o negativo, os mitos em relação aos outros considerados ciganos, desta maneira, recuperar as realidades históricas para que possamos pensarmos as comunidades ciganas, não como uma etnia unificada, más, com suas peculiaridades e diversidades. Recuperar a história, não com estereótipos para representa-los, mas com cidadãos de direitos iguais.

Isto posto, compreende que cada grupo cigano são detentores de costumes e práticas culturais que os determinam e diferem dos demais grupos sociais ciganos, chamando a atenção para as riquezas e diversidades de conhecimentos. Analisemos então, o começo do primeiro contato em campo:

\footnotetext{
-Pesquisadora: Por favor, a senhora pode falar seu nome completo? -Chefa: Ana XXX (fictício)

- Pesquisadora: A senhora é cigana?

-Chefa: sim senhora, do clã Calon, nasci em Valença-BA.

-Pesquisadora: o que é Calon?

- Chefa: É um grupo que tem origem no Egito e fala Caló, português, quem estuda fala inglês, outras falas e também ter envolvimento em comércio e troca de mercadorias. (ANA, 05/ 2019)
}

A partir do informe acima, Ana, me convidou a adentrar em sua barraca e arrastou uma cadeira para que pudesse aproximar-se deixando esperando por dez minutos. Diante dessa demora, procurei fazer algo que gerasse contribuições para a pesquisa e entendimento sobre aquela senhora.

Então, comecei a apreciar o cenário do estudo, o local externo era agradável, fresco, a barraca era de lona encerada de cor preta, com as laterais fechadas devido ao vento, o entorno da tenda havia um banheiro, a mulher cigana cultiva hábitos típicos tais como: criação de aves, na parte frontal do abarracamento tinha uma fogueira acesa que servia para afastar os insetos e cozinhar alimentos, a localização da tenda era no terreno plano, totalmente limpo à beira do asfalto, cedido por um gadjé (não-cigano), o ambiente interno da tenda representava: sala, quarto, cozinha, mas não apresentava divisões, por ser 
um vão único, tinha uma cama bem organizada, baús antigos, mesa de madeira, cadeiras plásticas, eletrodomésticos como: geladeira, fogão a gás, panelas brilhantes, louças tudo bem higienizadas, ambiente perfumado.

Em virtude da fala da chefa Ana, em vários momentos, notamos a demarcação de sua pertença, quando a própria assegura que é de uma etnia específica o Calon, e além do mais, deixa claro seus costumes, que os diferenciam de demais grupos ciganos e habitantes da localidade.

Segundo Ramanush (2012), os Romani (ciganos) tiveram a origem na índia, após muita pesquisa devido à falta de documentos. Contrapondo essa afirmação a declarante Ana, quando em entrevista perguntamos qual a origem do Calon ela informa que é do Egito.

Diante desse contexto, trago a contribuição da fala da cigana Stanescon (2007:15) em relação a origem cigana, a mesma destaca que desconsidera a hipótese que cita a índia como local de origem do seu povo, e relata que através de seus ancestrais sempre ouviu história dos antepassados egípcios, e afirma considerar que o povo cigano a que pertence veio do Egito, mesmo que as afirmações possa ser polemica e até ir contra toda enciclopedistas do mundo. E com base neste depoimento podemos confirmar que a origem cigana ainda é incerta.

Exemplificando essas questões da pertença a um grupo, tomamos como base o estudo de Giddens, descreve que, o nome é um registro da identidade individual, e ao especificar um nome damos importância também para a identidade de um grupo (GIDDENS, 2008, p.694).

Diante de tal informação, perguntei a Calin, se ela considera uma cigana brasileira? Imediatamente, ela respondeu explicando detalhadamente.

Vejamos então sua afirmação.

Nós ciganos é também nação da Bahia.

Quem nasce na Bahia é brasileiro.

Agora entenda [...] o nome que tem de cigano.

Somos Calon de Valença- Ba.

De origem Egito. (ANA, 12/2020)

Nesta fala podemos identificar a importância da demarcação da nacionalidade e integralidade de pertencimento e detalhamento de sua origem, bem como, o reconhecimento como cidadã brasileira.

Continuando a entrevista, observei em seu lar a imagem de Nossa Senhora 
Aparecida sobre o baú, e um porta vela antigo. A partir da verificação da imagem da Santa no cômodo, perguntei a Ana: qual a religião dos ciganos? A informante, ainda sem se aproximar da minha pessoa, respondeu-me da seguinte forma:

Olha, é católica, os Calon, são devotos de Nossa Senhora Aparecida. Mas! Têm os que frequentam as igrejas evangélicas, é livre, é a qual se adaptar e nos acolher (ANA, 20 / 2019).

Prosseguindo com sua narração em relação a Nossa Senhora Aparecida, a mulher Calin, narra que em seu grupo tem várias alternativas, muitos são católicos devotos de Nossa Senhora Aparecida, mas, reconhecem o valor da Santa Sara Kallí, outros são evangélicos.

Para ampliar mais este conhecimento Mota em seus estudos informa que "no Brasil, ciganos e não ciganos até conhece Santa Sara Kalí a cultuam, mas há alguns que desconhecem e consideram Nossa Senhora Aparecida como sua Padroeira" (MOTA, 2015, p.32). Compreendendo a narrativa proferida por Ana, na cidade de Jequié-Ba, notamos que a preferência pela Padroeira Nossa Senhora Aparecida, é devido ser a padroeira do Brasil, e ter a semelhança com Santa Sara Kali, além disso, o respeito motivado pela fé com sentimento coletivo, pois é através da fé que vigoram a pertença a seu grupo e ao amor divino.

De acordo com Lago, em seu estudo etnográfico na cidade de Maracás- Ba, sua participante de pesquisa faz a seguinte comentário sobre Nossa Senhora Aparecida, diz reconhecer a importância de Santa Sara, mas declara ser devota de Nossa Senhora Aparecida (LAGO,2020, p.53).

Analisando essas falas, podemos concluir que as autoras Barreto em Maracás e Rodrigues em Goiânia, alcançaram o mesmo resultado, de tal forma a minha participante deixa claro que o que importa é a pertença ao grupo e o amor ao divino.

As informações orais das mulheres cigana indicam ainda, que a existências das proximidades das divindades são perceptíveis em todos os clãs, sejam elas, patriarcais, matriarcais, todos elevam seus espíritos e vão construindo uma identidade que se embaralham aos elementos brasileiros, ciganos sobre a benção de um líder espiritual. Neste sentido, destacamos o pensamento Hilkner que diz: 
A comemoração a Santa tem muitas visibilidades e ocorre no dia 24 de maio, com procissões e considerado o tempo Kairólogicos, melhor dizendo, tempo de maior sacralidade pelos praticantes devotos de Santa Sara Kali, que buscam a graça nos olhos da Santa, pois neles encontra-se todas as forças de Deus, da mãe, amor, isto é, simboliza a Paz, neste espaço também neste dia é praticada a quiromancia que transforma todo o espaço devido atribuir a Santa o ato de dar o dom da linha das mãos a todas meninas ciganas.

Ana relata que a religião para um cigano é livre devido sua multiplicidade de crenças, e por ser livre diante a lei cigana e os Direitos Humanos, as Calins e os Calons, tem direitos de escolhas. Afirma que "hoje em dia, cada um tem sua fé, e por isso tem muitas divisões de religião. Analisemos a contribuição do Artigo $18^{\circ}$, dos Direitos Humanos que confirma esta escolha "

Toda pessoa tem direito de liberdade de pensamento, consciência e religião; este direito inclui liberdade de mudar de religião ou crença e a liberdade de manifestar essa religião ou crença, pelo ensino, pela prática, pelo culto pela observância, isolada ou coletivamente, em público ou em particular. (ARTIGO XVIII, p.35).

Entendemos com esta proximidade da lei cigana de deixar que seus componentes tenham livre escolhas de religiões é fator muito importante, pois assim, podemos compreender os valores de uma cultura, e ao mesmo tempo, podemos observar que não tem distanciamento entre a Lei Cigana e Direitos Humanos, mas o que ocorre e a forma como se olha o desconhecido.

Apreciemos então a imagem a seguir, mas, é importante antes, advertir que, seja na cultura Calin ou gadjé, cada cultura a recognição da Santa Sara e Nossa Senhora Aparecida, terá outras representatividades, por isso, necessitamos sempre ponderar os acontecimentos.

Diante desse contexto, Ana, fala que um acampamento o lar cigano com o altar de Santa Sara Kali, ou de Nossa Senhora Aparecida, são casas protegidas e abençoadas. E segundo os estudos de Geertz (1989) "ele vê os símbolos como transmissor de cultura".

Por outro lado, em campo foi possível perceber através dos encontros com a Calin, que as mulheres ciganas em seu sagrado além do culto a Nossa Senhora Aparecida, ao mesmo tempo, cultuam os elementos da natureza, entre eles o fogo, o ar, água, a terra, além do cosmo sol, lua e astro, do mesmo modo as plantas medicinais, tais elementos compõem o panteão sagrado, além da dança que também acompanha a vibração energética. MIRCEA (1979) em seu estudo sobre o sagrado o define: [...] "o sagrado pode se revelar em qualquer espaço, objeto, 
qualquer elemento, que por indivíduos, tenha relação com o sobrenatural" (MIRCEA, 1979, p.13).

A Calin informa que em sua tradição tem conservado o sagrado da natureza, e assim, as montanhas, rios, pedras, a flora e a fauna, tem um auto significado para cada cultura e todos rituais são diferentes, e consisti a ser empregadas em torno das narrativas de forma orais. Os homens não participam dos rituais sagrados nas culturas ciganas, assim, este papel é destinado as mulheres.

Desse modo, a Calin informa que tempos atrás o ritual era feito em sua maioria a beira mar, cachoeiras, é um ritual oriental com muita dança ritualísticas, muitos chás com especiarias da índia, canela entre outros. Mas que atualmente estas ritualística entre os mais novos estão se acabando.

Outro marcador que traz grandes problemas para a etnia cigana é pensar que toda cigana vestida de vermelho, julgam estar relacionados a Pomba-gira, aí começa os estereótipos, isso ocorrem devido os gadjés, pensarem que cigano é uma religião, mas não é.

Partindo dessa mesma linha de raciocínio, faz-se pertinente aqui mencionar que não se devem assemelhar-se os rituais da cultura cigana as entidades da Linha do Oriente, isso deve ser separado em partes. Todavia, as ciganas na cultura prezam por elementos da natureza, os astros e os ancestrais conhecidos como magia elementar.

Com relação a linha do oriente, não atuam apenas na Umbanda, mas também no Candomblé, eles operam em todos os centros em que são aceitos e bem recebidos, porém, nestes espaços há uma hierarquia espirituais ciganas e ciganos. Quando pensamos a linha do oriente, falo do princípio de origem de agrupamento de espíritos de várias tradições, tempos, níveis de conhecimentos e graus evolutivos, devido trabalhar curas ancestrais.

Nas entrevistas feitas em campo, foram nítidos os relatos que envolve os valores dos elementos da natureza, como a água o ar e a terra, o fogo que foi o primeiro elemento presenciado no acampamento pela fogueira que em nenhum momento fica apagada, e tem a seguinte simbologia: espantar mosquitos e os mal espíritos, ciganos que estão nas estradas utilizam o fogo para afugentar os animais na floresta, além do mais, é um fornecedor da vida, pois serve para cozinhar os alimentos, além disso, importante para os ferreiros e alquimistas, já em relação a vestimenta a cor vermelha assemelha ao fogo, a sexualidade, a paixão, mudança, 
bem como, o poder no conhecimento divino, quer dizer, está ligado ao plano espiritual.

A água por sua vez, também é um produto fundamental para o ser humano é o princípio da pureza e da impureza, da limpeza e da renovação e sua junção água e fogo são utilizados em rituais místicos, representa a esperança do iniciado, a água é um espelho mágico de elemento ocultista, além de estar ligada as emoções e aos sentimentos e fazer parte do nosso corpo através do sangue, saliva, além de trazer fluidez e flexibilidades.

O ar representa a mente, isto é, o pensamento, entendimento, conhecimento, além de ser importante para a sobrevivência. A terra significa a segurança a verticalidade das árvores, raízes, em outras palavras, é hora de crescer com os conhecimentos adquiridos. Em relação a dança [..] "O ar representa os véus; a água ondulações das mãos; terra vem com movimento e crescimento de uma árvore; o fogo movimento da serpente e ondulatório do quadril [...]". (HILKNER, 2008, p.189).

Entende-se nesse contexto que toda cultura e até praças de várias cidades tem sua paisagem cultural contemplando os elementos da natureza como por exemplo Praça do Cruzeiro Paisagem Cultural em Brasília.

Com embasamento nessas observações e na entrevista a Calin, envolvida com a questão dos elementos, exclamou, chamando a minha atenção para a importância dos elementos, afirmando que, com os quatro elementos podemos conhecer nosso corpo, nossas atitudes, eles se completam, um não pode existir sem o outro, assegurou ainda que, com estes elementos podemos conhecer nossos signos, pois temos signos do fogo, do ar, da terra, da água, podemos classifica-los, além de conhecermos outras culturas.

Outro tópico que a Calin sempre fala rapidamente, que me chama atenção é a questão de andar sem calçado, pois acreditam que é uma forma de descarregar energias na terra, e ao mesmo tempo, absorvem energias positivas emanadas do céu, do sol, da lua e das estrelas e quando necessário as mulheres utilizam havaianas, tamancos ou botas.

Em relação aos quatro elementos da natureza em outra cultura, trago a reflexão de Azevedo (2019) que fala sobre a representatividade dos Orixás com os quatro elementos. Avaliemos, então: 
"[...] cada orixá está ligado a energia do planeta terra, assim a água, a terra, o trovão, o fogo, raio e sol e as folhas que nascem tem ligações essenciais onde a vida e energia [...] sem a força da natureza não existe os orixás"

(AZEVEDO,2019, p.20).

Com base na análise, concluir nesses relatos e explicações, que os cultos aos sagrados, valores e expressões de cada cultura e crenças, afirmam a identidade étnica de uma pessoa ou de um grupo, até mesmo de uma sociedade e que a afirmação feita pela participante traz as clarividências das relações entre sagrado, indivíduo de qualquer cultura, indicando atitudes, atos, o mesmo pode levar ao divino como o sobrenatural.

Por outro lado, a cultura cigana tem muitas crenças e tradições e também muitos símbolos, que são valorosos que retratam o mundo espiritual entre o cév e a terra que estão ligadas às pessoas, e devem ser carregados segunda a fala da declarante na vida e na morte, devido simbolizar a proteção trazendo a luz, que faz conexão com o divino de acordo com a importância de cada indivíduo.

Consideremos então a fala da entrevistada Ana, relacionada aos símbolos.

a coruja simboliza segurança; a chave simboliza as soluções dos problemas e atrai riquezas; a estrela de cinco pontas, simboliza a evolução, sorte; a estrela de seis pontas, simboliza um talismã contra amigos visíveis. Invisíveis, e representa o símbolo dos chefes ciganos; a ferradura significa sorte; a lua é um dos principais ingredientes da magia do mistério, poder feminino, cura; a moeda simboliza a prosperidade; a roda simboliza o ir e vim dos ciganos; a taça simboliza união eterna; o trevo significa sorte; o punhal significa força poder e vitória. (ANA, 05/2019).

Para Eliade "o símbolo, o mito e a imagem pertencem à substância da vida espiritual, e que às vezes pode-se até camuflá-los, mutilá-los, decapitá-los [...], mas nunca se pode extirpá-los" (MIRCEA, 1979, p. 12). Enfim, entendemos que os símbolos e algo importante para uma cultura e não podemos desvaloriza-la pois faz parte da construção da nossa identidade.

Com a sequência das conversas informais começar as entrevistas propriamente dita, Ana, serviu um café em busca de obter confiança, e articulou, agora vamos conversar, assegurou que o diálogo seria prolongado, diante desta afirmativa, entendemos que a busca pela confiança estar arrolada ao diálogo. O diálogo é ponto importante para o conhecimento da história de uma cultura e grupos diversos e para reconhecer o sujeito na qual estamos interagindo, como também, podemos respeitar a outra pessoa e ser respeitado.

Queiros (2003) "nos diz que o diálogo nada mais do que a ação de dialogar, 
de trocar ideias e informações por meio de trocas verbal. Foi entre dois ou mais interlocutores que chegaram a uma verdade comum".

A partir desse momento, pedir consentimento para gravar, foi permitido, diante dessa situação, peguei o celular, a entrevistada de forma natural começou a discorrer, avisou que não gostava de interrupções, falou o seu nome Ana, que sua idade era de aproximadamente 67 anos, nacionalidade de Valença-Ba, mais que a muito tempo está fixa no município de Jequié, porém, não sabe quando chegou na cidade, residiu em vários bairros e zona rural, que não estudou por que viajava e trabalhava muito com seus pais e por isso não sabe ler.

Continuando com seus relatos, a informante destacou que hoje as mudanças são contínuas e que sua família se movimenta no munícipio com trocas de carros, vendas de confecções, que atualmente são comerciantes e mesmo com todas as mudanças mantem as características fortes da cultura, destaca ao mesmo tempo que, vive o amor e respeito, informou que é viúva e líder do grupo Calon, e que em relação aos seus avós, não conheceu, mas sua mãe afirmava que era Calon.

Diante dos relatos da Calin, fiz a seguinte pergunta: conte-me um pouco sobre suas lembranças da infância e quais suas brincadeiras favoritas? E ela respondeume da seguinte forma:

\footnotetext{
"Na infância brincava com boneca de pano com olho, brincava de roda no tempo de lua, e quando chegou o tempo do casamento foram três dias de festas, com cantor, muita comida, bebidas e festa no Club" (ANA, 06/ 2020).
}

Sobre o mesmo ponto de vista, Friedmann (2012) esclarece que, através das atividades lúdicas, as portas para o mundo social e para as culturas infantis vão se abrindo possibilitando igualmente o impulsionar para seu desenvolvimento. Com tal intensidade podemos afirmar que o lúdico facilita o processo de socialização e construção de conhecimento.

Percebemos que a brincadeira fornece a criança à possibilidade de construir uma identidade independente cooperativa e criativa em todas as etapas da sua vida, pois é através da brincadeira que vão conhecendo a si própria. Além de que, os contatos com outras crianças possibilitam experimentar situações da vida ora de competição, medo, alegria ou tristeza.

O brincar é nossa primeira forma de cultura, e nesse contexto trouxemos a explicação de Ângela M. Borba (2007, p.12) que aponta a seguinte afirmação: se 
entendermos a infância como o período em que os seres humanos está se formando culturalmente, a brincadeira ela vem se tornar importância fundamental como forma de participação social, como atividade visa possibilitar apropriação, a ressignificação e a reelaboração da cultura pela criança.

É fato que as relações atualmente estão diferentes. Mas, não podemos esquecer que o ato de brincar, faz parte da vida do ser humano, seja nas brincadeiras de roda ou das tecnologias, pois fazem o indivíduo excitar sua inteligência e se adaptar ao espaço que vive. "A construção da Identidade está interligada com o contexto (CASTELLS, 2008), tendo em vista que todas as intervenções sociais e as características de cada tipo de Identidade conectam-se ao ser social[...]".

Diante desta entrevista de trinta minutos, narrada fluentemente pela participante, compreendi que os detalhes disponibilizados pela líder cigana poderiam ser conduzidos de outra forma, em virtude das riquezas das ideias expostas que no primeiro momento da entrevista teve reciprocidade, em vista disso, surgiu então o diário de campo para particularizar os episódios relatados.

A partir dos acontecimentos aqui exibidos e observações realizadas, em campo decidir fazer as perguntas sobre o processo de socialização nas diferentes etapas da vida, já que ela tinha dito seu nome, idade, local e data de nascimento, avós, pais, trabalho, viuvez, que é líder do clã Calon, procurei desenvolver um panorama em relação a construção da identidade étnica da mulher Calon, tendo início desde a infância até a velhice.

Nessas expectativas, podemos afirmar que "[...] enquanto indivíduos, estamos imersos em ambiente que propicia uma base para a constituição da nossa identidade. Essa identidade torna-se, assim fruto do processo de socialização" (BERGER; LUCKMANN, 2003).

Para facilitar a compreensão, iremos tratar sobre as relações familiares por ser o processo de socialização primária na vida de uma mulher cigana que começa na infância e envolvem toda organização de grupo, como as obrigações doméstica de gênero, aprendizado da linguagem, padrões de comportamentos recebidos como normas, valores da lei cigana, começando sua formação social com a interação com o outro na vida cotidiana de forma gradativa e relacional, além disso, o ambiente deixam marcas profundas em sua vida devido ser o espaço que permitem construir o seu mundo com amor e respeito e sem regras. 
As brincadeiras de criança, os afazeres na barraca possibilitam entender que o imaginário infantil enriquece com as experiências vividas pelas crianças, pôr ser significativo para o processo de socialização. De tal modo, a partir delas os papéis sociais começam a ser construídos de forma lúdica, processo esse que possibilita uma identificação de gênero, além do mais, a arte de criar símbolos permeia a criança para a vivencia em grupo. "A brincadeira é uma atividade que a criança começa desde o seu nascimento no âmbito familiar" (KISHIMOTO, 2002, p.139) e continua com seus pares".

A líder Ana informa que na contemporaneidade, um dos fatores que está fazendo parte da socialização primaria para as crianças Calin, é a escola a mídia, elemento este de transformação que não existia tempos atrás. Ainda mais, quando inicia a divisão do trabalho para distribuições de conhecimentos e papéis sociais, passar a existir então a socialização secundária (hábito de grupo.), para novos campos de relacionamentos períodos este com aprendizagem diferenciadas.

$\mathrm{Na}$ mesma linha de entendimento, a socialização secundária em uma organização cigana, estabelece as questões do trabalho normas e valores que são instruídas para os dois gêneros, masculino, feminino, auxiliando sempre para o aprendizado até o fim da nossa vida. Todo aprendizado é fundamental e saudável na cultura cigana para que permita identificar qual é atividade relacionada ao homem, mulher, assim, vão construindo sua identidade a partir das relações e experiências adquiridas no espaço familiar onde vive.

Igualmente, a personalidade é estabelecida gradualmente a partir da interação com outras pessoas, especialmente com a família. Aprendemos que tudo tem início na infância, a partir dos primeiros contatos na família, enfim, é um processo dinâmico onde as características individuais são construídas, mudanças ocorrem no decorrer do tempo, entre as relações familiares, culturais, classe sociais, meio onde estamos inseridos contemplando assim as nossas experiências de vida.

Para uma compreensão ampliada trazemos a narrativa de Ana, em relação a sua infância com sua família no cotidiano, em que o respeito, amor sempre permanece presentes na tradição, assim como, a busca do sustento familiar para a sobrevivência. Para somar aos resultados dessa pesquisa, citamos agora a realidade de Ana e seus pais no período em que viviam em trânsito, de um lugar para outro. 
A família toda! Lutava a cavalo, lutava a bater barraca, lutava a acender fogo, lutava a pegar burro pra fio amuntar. Tá entendendo? Viajava, chegava lá tornava a arriar. Batia barraca, batia barraca. Cendia fogo, pegava lenha, panhava água, coava café, fazia de cumê dava os fi. Quando era noite botava para dormir. Quando era no outro dia, lavava roupa. Era naquela vida, tá entendendo? Ontonse quem tinha estambo e coragem fez sua família. Aí a vida continua pra frente. A cavalo, a burro a carro não que foi por agora, de primeiro era o boiadeiro, tocando a boiada, os tropeiros. Tudo isso pela estrada, pegando o sustento. Lutando com Deus (ANA, 05/2019).

Tomando como base esse discurso observamos que a união familiar é alicerce desse grupo e que atividades comerciais como a troca de animais são importantes para os períodos das viagens o trânsito de um Estado para outro, e manutenção da sobrevivência que ocorrem até os dias atuais devido o comércio fazer parte da tradição. Um dos destaques nesse relato de grande valor, é o aspecto físico que Ana, demarca da seguinte forma "que tem estambo" e coragem faz a família, assim dizendo, que tem força e coragem vence a vida, a descrição demonstra também o preparo que se deve ter para construir uma família.

Nesta entrevista também foi notada a expressão de gratidão a Deus, por todos da família estar sempre juntos, Ana, revela ainda que a gratidão é boa para o estado físico mental e para a questão de ordem, e para o trânsito cigano. Para somar, percorramos a contribuição de Elisa Lopes Costa (2001) que cita a viagem cigana como fundamental por fazer parte de sua realidade cultural, social e econômica. A autora ainda pontua que seus modos de vida podem ainda revestir de três forma: nomadismo, semi-sedentarização e a sedentarização.

A Calin relata ainda que, tempos atrás, trabalhavam tocando boiada, como tropeiro e boiadeiros. O termo tempos atrás, em sua fala podemos entender que há um sentimento de saudade no tempo de suas andanças, melhor, guarda o tempo de intinerância na memória e limitações no estilo de vida, onde foi construída a identidade do grupo. Não só, como também se nota a importância das tarefas domésticas para cultivar a união de pertencimento ao grupo, lugar este que se encontra o aprendizado da cultura cigana, compondo de tal modo o universo simbólico, cultural do saber básico na infância, o incentivo as crianças auxiliando nos afazeres da casa, demostra o estímulo a ter noção de limpeza, organização, de planejamento, de trabalho coletivo e familiar, bem como, preparar para a vida adulta.

Monteiro \& Goldfarb (2017, p.69), aponta que "a infância para os ciganos 
compreende, portanto, fases sucessivas do momento de proteção, de aprendizagem e de preparação para torna-se adulto, dessa maneira, compreende-se que a partir do momento que se torna adulto prepara-se para ter sua família". E sobre esse prisma, a família é unidade básica de grande importância na vida da comunidade Calon, e a chefa da família figura da liderança.

Na dinâmica das falas de dona Ana, podemos entender o lema que é dito por todos os ciganos "O céu é meu teto, a terra minha pátria, e a liberdade é minha religião". Traduzindo esse lema, entende-se que a maior motivação é a busca pela livre-arbítrio fator primordial. A alvedrio em um grupo Calon, é uma flexibilidade de tempo e espaço para manter sua identidade étnica e cultural, é prezada acima de tudo, uma vez que o importante é conservar a sua unidade familiar. Não há dúvidas que, a preservação do tempo com a família no acampamento, viagens coletivas, visitas a acampamentos de parentes para fortalecer laços de amizades e apresentar suas conquistas é essencial. Na história cigana sempre se fala da movimentação da família cigana de um lugar para o outro, fato corriqueiro, mas, é notório que neste movimento é que vão formando sua identidade que compõem desde a forma que se organizam, proferem, e sim, é importante que estas movimentações sejam respeitadas, porque cada família tem seus próprios movimentos que processam mudanças no decorrer de sua vida.

Retomando a citação de Monteiro \& Goldfarb não podemos esquecer que a infância das meninas ciganas, termina após o primeiro fluxo da menarca, que sucede entre 10 e 14 anos, é quando deixa a infância, passa para a fase adulta, é nesta fase que as mulheres ciganas começam a aprender o que é membro de fato Calon produtivo no grupo, participando com adultos do mesmo sexo de atividades familiares, onde passam a assumir responsabilidades sobre seus próprios atos, fatore que marca o costume e tradição no grupo, pois este período começa nova composição familiar a ser construída dando início a preparação para o casamento.

Dentro da festa do matrimônio, as mulheres ciganas têm o direito de dois a três dias de festas, mas em alguns grupos pode ser mais de uma semana, pois a felicidade e alegria define a vida e o matrimônio de uma mulher cigana e devido ser um momento de contentamento são convidados ciganos de todas as comunidades no geral.

Em uma cerimônia, as festas são diferentes das brasileiras, além da duração 
de três dia de festa, cada dia são representados de uma forma, no primeiro dia, a noiva é apresentada ao noivo, com almoço ou jantar fica a critério dos pais da noiva, no segundo dia, ocorre a cerimônia, na religião decidida pelos noivos, a festa começa no terceiro dia e vai até uma semana depende das condições familiares.

Outros detalhes preciosos apresentados nas entrevistas foram a história em relação ao seu casamento, que narrou da seguinte maneira: "casei nova, com 16 anos, bonita, passei boa vida, foi três dias de festa, muita gente, muita comida, bebida, cantor, festa no Club (ANA, 05/2019)". Considerando o conto da participante da pesquisa, sobre a sua união, pediu para que aproximasse de seus baús, retirou de dentro um quadro envolvido em pano branco, com uma fotografia confirmando o que tinha dito.

Em uma primeira análise, entendemos que a memória cultural preservada através do retrato, marca a construção da própria identidade, de acordo a contribuição a autora Maria Fernada Seixas Farinha Beirão, faz referência a Kossoy (1989, p .14), "toda fotografia representa em seu conteúdo uma pesarmos a fotografia como registros simbólicos da preservação da memória da família de tempos felizes que jamais existirão novamente.

Ademais, a citação de Kossoy, relacionada com a condição marital de viuvez que se encontra a participante, por não poder casar-se mais, o ponto de relevância nesta foto é correspondente ao seu consorte ter sido o líder do grupo, e relembrar a sua união matrimonial é indicativo de que ele foi um bom companheiro em sua vida que tal imagem representa também suas diferentes idades, além de marcar a formação do grupo por um patriarca e também um patrimônio cultural.

Na cultura cigana, as mulheres Calin, como são chamadas em seu convívio, se casam cedo, para elas é cultural, natural, sabe-se também que, neste período de preparação não existe namoro, e não pode se beijar nem na frente dos pais, sogros, nem de outras pessoas, não se pode discutir sobre relacionamentos, isso é desrespeitoso na cultura cigana, não se deve falar nada sobre amor.

Analisando a resposta da participante sobre seu casamento, perguntei quem escolhe atualmente as esposas para os filhos?

Ana responde que "antigamente era os pais que arranjavam o casamento e hoje, eles escolhem, gostando, casam-se e vive, podem casar cigano com brasileira, hoje ciganos, ciganas tem direitos, deveres, aqui no nosso grupo". A partir 
desse relato, achei interessante a questão do direito de escolha, fato não comum entre as comunidades ciganas, em razão das comunidades ser diversificada com costumes, leis, valores também diferenciados e rígidos.

Questionei, como assim? Ana, continua a especificar os fatos informando que ciganos pode se adaptar aos progressos, estudar, fazer faculdade, mas não deixando suas raízes ciganas e que o avanço é importante para a cultura, e afirma que as raízes principais da cultura são o respeito as crianças, o respeito aos idosos e isso não pode ser deixado para trás, pois faz parte da lei cigana, já que é uma tradição permanente na cultura. Consideremos então a fala de Ana.

Hoje pode trabalhar, ter profissão, estudar, os homens namorar com
brasileiras e as mulheres com brasileiros, antigamente não podia, hoje se
quiser vai para a escola se não quiser não vai, e a vida segue em nome de
Deus, mas sem deixar a tradição, seguindo a lei cigana (ANA, 05/2019).

Como vimos nos relatos, a interação social é importante para que as culturas se modernizem com o passar do tempo, e as histórias individuais e coletivas interligam ao convívio criando novas experiências e conhecimentos e assim sendo, culturas vão se miscigenando, atualizando-se, tais situações ocorrem em consequências das adaptações aos novos ofícios para a sobrevivência no mundo atual e nesse ínterim acontecem os relacionamentos.

Em virtude do relato sobre as questões da escolha é preciso esclarecer que na maioria dos grupos ciganos o namoro com jurin é só permitido ao homem e a mulher não, uma vez que significa vergonha para o grupo e assim ser expulsa do grupo caso venha a descumprir a lei cigana. Cabe destacar também que a historiadora Cassi Ladi Reis Coutinho em sua pesquisa faz a seguinte análise sobre o casamento Calin com gadjó5. Observemos o que ela diz:

Mas o casamento entre uma mulher cigana e um gadjó é envolto em preconceito e resistência por parte do grupo, pois estes entendem que o homem poderia isolar a mulher e os filhos do casal, prejudicando o fortalecimento da família cigana. (COUTINHO, 2016, p.42).

Com base na análise, entende-se que a lei cigana é fundamentada na palavra dada, por não ter escrita é passada oralmente e consequentemente não poderá ser descumprida nenhuma regra e nenhuma concordata, pois existem sanções rigorosas, bem como, é desmoralizado face a face a sociedade cigana.

Outra forma de conceber as regras da lei cigana, de acordo a informante

5 Termo usado pelos ciganos quando se referem a um não cigano. 
da pesquisa é manter o casamento tradicional dentre grupos ciganos de mesma etnia, Calon com Calon, Sinti com Sinti, Rom com Rom, tem suas realizações entre primos de segundo, terceiro grau, fator primordial para a continuidade da tradição.

A tradição cigana, traz modalidades que devem ser seguidas determinando a obediência as leis ciganas, como por exemplo: quando criança a menina obedece ao seu pai; na juventude cumpri ordens dos pais e irmãos; casada respeita exclusivamente ao marido; quando chega a velhice obedece aos filhos, caso não tenha filho ao genro, mas, ao genro caso não tenha filho do sexo masculino.

Para contribuir com a questão do casamento, precisamente em relação ao dote, mencionamos Ramanush (2012) assegura que: o dote é de encargo do pai do noivo pagar ao pai da noiva em honra a sua pureza, o mesmo deverá ser pago em darro (ouro) que representa o futuro do casal. Por isso, o dote é de grande valor em uma cultura cigana, caso a mulher não seja virgem o noivo pode devolvê-la no dia seguinte.

Ana, conta que a festa da etnia cigana é uma expectativa da noiva, é momento esperado por todos onde a noiva usa-se dois vestidos: o branco na igreja no primeiro dia, o vermelho no segundo dia simbolizando o fim da virgindade. Posto isso, a Calin dá início sendo a provedora do lar, da família, e também da responsabilidade dos mais velhos, todavia, é interessante frisar, que nem todos casamentos de comunidades ciganas tem a mesma união típica e festas iguais, pois os grupos têm hábitos e ritos diferenciados. Vejamos então, as variedades de casamentos e ritos em algumas comunidades, conforme Manuel A. Arantes da Costa (2006, p. 194):

Os rituais do pedido de casamento variavam muito de comunidade para comunidade. Assim, nos ciganos da Transilvânia, era o rapaz que escolhia a rapariga oferecendo-lhe um lenço de seda vermelho que colocava à volta da tenda da sua família. Noutras comunidades utilizavam-se intermediários para demonstrar os sentimentos do futuro noivo, oferecendo à noiva flores, lenços ou peças de ouro. Para outras comunidades, como por exemplo, entre os ciganos da Bélgica, da Suíça e da Espanha, o ritual era do tipo patriarcal. Os jovens não tinham iniciativa nenhuma, sendo o pai do jovem que procurava a noiva. A intervenção do pai, ao procurar a noiva para seu filho, seguia, também, um ritual. Assim, o pai da noiva ao aceitar beber um copo de vinho oferecido pelo pai do jovem, significa que ele aceitava o jovem para a sua filha. (COSTA, 2006, p. 195).

Com base na citação, observamos que em relação ao estudo de Costa, a 
cultura cigana ela conserva seus valores, regras, rituais que estão em todos os grupos ciganos ao redor do mundo e são passados de gerações e gerações reconhecendo assim sua essência.

Outro ponto importante no grupo Calon, é a velhice, fator esse por ser guardiões da sabedoria e fazer parte do ciclo da vida, são eles capazes de proteger todos do grupo, em razão disso, são passados desde infância seus conhecimentos. Todos os acampamentos, seja ele de linhagem patriarcal ou matriarcal, tem uma referência feminina que é uma mulher mais velha do grupo, como também, uma figura masculina representada por um homem mais velho do grupo, onde se deve o respeito sempre, devido os mais velhos ser a ponte de ligação entre os ancestrais.

Ainda na mesma linha de pensamento, a ligação com a ancestralidade não está exclusivamente no fato de ser idoso, mas sim, estão expressas através dos corpos das mulheres ciganas onde levam a representatividade de toda a sua ancestralidade e neste contexto, cada clã representa a sua ancestralidade conforme sua tradição.

A ancestralidade em seu contexto geral é uma categoria relacional, já que não existe ancestralidade sem uma alteridade e sendo assim, acontecem a partir das relações, seja uma relação onde as pessoas podem se confrontar ou se relacionar.

Nesta próxima parte deste capítulo, caminharemos para a segunda participante da pesquisa.

\subsection{ELIANA, SEGUNDA PARTICIPANTE DA PESQUISA}

Partiremos agora para a história da nossa segunda participante de pesquisa Eliana, a escolha em relação a brasileira se deu por meio das visitas ao acampamento da mulher cigana, decorrente a observações e afinidade comerciais e religiosas entre as duas. Essas proximidades na comunidade cigana se dão por afinidades que está relacionada ao respeito ao outro em aprender, de se comunicar, analisar o mundo que o cerca. A afinidade é base para uma amizade com confiança, diálogo e limites, além da questão da religião por frequentar a mesma igreja.

Na adjacência do acampamento, as mulheres Calin, começam se 
organizarem adequando-se ao ambiente da população local, deste modo, a circunvizinhança da localidade tem hábitos que são parecidos com a vida cigana, em relação ao comércio, na beira do asfalto é visível avistarmos debaixo de árvores barracas de vendas de verduras, toalhas de pratos, cama, mesa e banho, trocas de animais, carros, realizados por ciganos e não ciganos, entre outros.

Tendo em vista as atividades comerciais, Eliana sempre saí convidando pessoas no bairro e convidou Ana, para comparecer a igreja evangélica, e sempre um dia antes do culto vão nas casas das Calins e brasileiras, pois este hábito é comum no bairro, devido ter próximo igrejas neopentecostais e um desses convites a nossa participante da pesquisa Ana, aceitou, assim começou a frequentar a igreja.

Também devemos esclarecer que em grupos ciganos, onde nem todos os componentes são evangélicos é necessário que tenha limites de trânsito entre o dito evangélico, com as jurin 6 , em respeito aos demais componentes dos grupos para que a harmonia permaneça na organização cigana.

A movimentação neste comércio é constante, neste ambiente, Eliana, entrega folhetos evangélicos e está sempre dialogando com Calin e brasileiras, para que as mesmas aprendam como chamar outras pessoas para participar dos cultos, foi o ponto que deu início a escolha. Diante dessas escolhas observamos que as participantes se encaixavam na temática das Relações Étnicas.

No percurso dessas observações no acampamento, resolvi comparecer até este pequeno comércio de verduras para descobrir o endereço de Eliana, e ao perguntar, logo, deram a indicação, fui até à sua residência, chegando lá, me identifiquei como estudante e que estava pesquisando sobre comunidade cigana nas extremidades e inquiri se podia ajudar participando da pesquisa. Ela disse que participaria, imediatamente, questionei se podia fazer umas perguntas e marcar um agendamento, ela aceitou, continuamente para ter um diálogo aberto improvisei as perguntas devido a informante ir para o culto.

Nesse primeiro contato, apreciemos as respostas de Eliana

\footnotetext{
- Pesquisadora: qual seu nome?

R: Eliana $x x x$ (nome fictício).

- Pesquisadora: qual sua data de nascimento e local?

R: Eliana: não respondeu, local Jequié

-Pesquisadora: idade, sociedade civil?
}

${ }^{6}$ No Nordeste do Brasil, os gadje são chamados juron e jurin. 


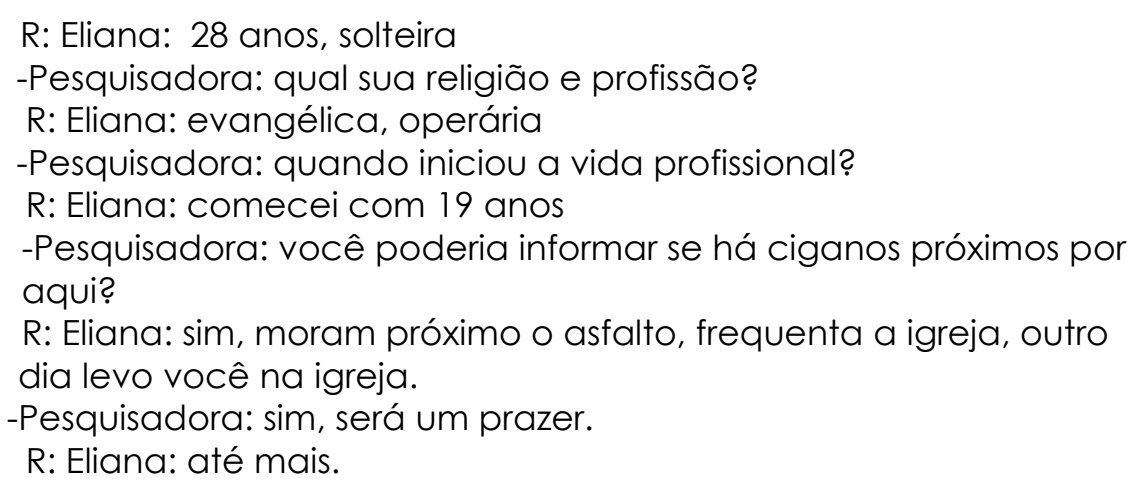

Dias depois, o encontro se repetiu na residência de Eliana, a receptividade foi excelente, inicialmente serviu um cafezinho e informou quando nós recebemos uma visita tiramos uma passagem da Bíblia para o visitante, em continuação ela pergunta se eu aceito, respondo que sim, então começa o nosso segundo diálogo.

Diante das primeiras perguntas iniciais, feitas no primeiro encontro, o convite para ir à igreja, me rememora o conceito de Hall (2006, p.11) que fala da identidade influenciada pelo meio social, verifiquemos então a reflexão.

De acordo com essa visão, que se tornou a concepção sociológica clássica da questão, a identidade é formada na "interação" entre o eu e a sociedade. O sujeito ainda tem um núcleo ou essência interior que é o "eu real", mas este é formado e modificado num diálogo contínuo com os mundos culturais "exteriores" e as identidades que esses mundos oferecem (HALL, 2006, p.11).

Compreende-se que a identidade cigana de acordo o conceito de Stuart Hall, ela está sendo questionada, as mesmas deixam de ser unificadas e passam a ter várias identidades, seguido assim, as mudanças da sociedade contemporânea, bem como, o eu e o outro.

Para expor como eram as aproximações iniciais dos primeiros evangélicos na história ao longo das décadas, com propósito de conversão, aludiremos a dissertação Guimarãis (2012, p. 167), sobre "O Associativismo Transnacional Cigano: Identidade, Diásporas e Territórios". Afirmando que:

Os primeiros contatos entre os evangélicos históricos e ciganos com o propósito de convertê-los ocorreram no século XIX, quando a International Bible Society de Londres enviou os primeiros missionários para os Pirineus $e$ produziu as primeiras traduções do Novo Testamento para o romanês. Na Europa Oriental, a pregação evangélica começou no início do século XX, com os primeiros missionários chegando aos Bálcãs nos anos XX (GUIMARÃis,2012, p.167).

Nesse sentido, o autor relata que a partir dos anos 50, o neopentecostalismo ganhou investida com a questão da evangelização de ciganos tornando o movimento mais importante transnacional entre os ciganos e ao mesmo tempo 
superando as divisões entre grupos ligados a uma plataforma comum.

As relações Interétnicas entre ciganos e brasileiros evangélicos e entre ciganos convertidos e não convertidos estão se desenvolvendo devido o investimento das igrejas protestantes em relação a etnia cigana. Por conta disso, as atividades desenvolvidas entre ciganos evangélicos convertidos, passam por mudanças, que acontece com a conversão.

Segundo Gomes (2011, p. 157) a conversão pode ser entendida como sinônimo de mudanças e transformações.

\begin{abstract}
Esse termo comporta uma ideia de transformação, tanto no nível das crenças como no nível das práticas. A dimensão de mudança de percepção do mundo representa de resto o único consenso que os investigadores em ciências sociais estabelecem em torno do conceito. A conversão evoca "mudança de coração", "um processo de mudança do senso de realidade", ou ainda, "um deslocamento da consciência em seu sentido aterrador".
\end{abstract}

A fala de Gomes, nos remete a pensarmos a conversão como algo individual do ser humano que possibilita uma mudança interna, digo, do interior para o exterior. A cura estabelecida nas pessoas frequentadora ou convertida da igreja evangélica, é o ponto que influência a permanecer na igreja, sendo estes ciganos ou brasileiros.

Para BARTH, (201 1, p.204) em seu livro Grupo Étnico e suas Fronteiras ele relata que as relações interétnicas são processos que transformam as identidades individuais, grupais, que prevalecem além de modificar os fatores demográficos que precedem nas situações.

Ainda com apoio no conceito de Barth, podemos afirmar que as interações sociais intervêm nos fatores demográficos, e prevalecem nas situações subjetividades e vivências de um grupo, assim, vão construído suas identidades nas interações com as outras pessoas.

Diante do exposto relataremos a partida ao culto com Eliana, que deu início às 19:00 de uma quinta-feira, 24 de julho de 2019, e lá estava Ana a outra participante da pesquisa, que na igreja saudou-nos com a Paz do Senhor (Patch le Deuleski) nós respondemos paz, sentamos juntas, assistimos o culto que foi maravilhoso, no final conversamos um pouco.

A nossa interlocutora Ana, afirma que não é convertida na igreja evangélica, mas sim, frequentadora, pois a palavra de Deus não pode ser negada a ninguém nem as ciganas. É notório, que na igreja que frequenta os sinais diacríticos da sua 
tradição permanecem tais como: as vestimentas ciganas coloridas, os dentes de ouro, os brincos, já no caso de dona Ana, que veste roupas azul escuro e saia preta também não é proibido, devido ao uso da veste ser o costume da sua cultura. Assim sendo, as mulheres ciganas convertida a proibição só está relacionada na leitura das linhas das mãos, danças, bebidas, em relação a venda de figas em praças públicas, agiotagem, já em relação a brasileira, estão as questões da bebida e festas e namoro.

Mediante tais reflexões, surgem duas perguntas singulares em relação a vida comunitária para que Eliana, responda, vejamos a seguir: Na sua comunidade o que é bom para você e o que não te deixa feliz? Eliana responde da seguinte forma:

bom, para mim e ser evangélica. O que não me deixa feliz, é saber que os ciganos não são aceitos pela maioria da comunidade Jequieense, e que o desconhecimento sobre a etnia, faz com que os estereótipos permaneçam até os dias atuais tornando a vida dos ciganos difíceis.

Corroborando com essa resposta de Eliana, trazemos a contribuição de Lucena (2016), "a sociedade brasileira desconhece a cultura cigana e não consegue entender a maneira de viver desse povo como nômade ou em comunidades." (LUCENA, 2016, p. 19).

A informação de Lucena, traz à tona o preconceito que as ciganas passaram pelo fato de serem ciganas, essa problemática 'é mundial, e por ser algo que contempla várias sociedades, observa-se 0 distanciamento e 0 desconhecimento e falta de interesse em conhecer uma cultura e assim vão gerando as violências contra as comunidades ciganas. Muitas pessoas falam que os ciganos não fazem parte do cotidiano gadjé, mas podemos encontra-los em toda parte, escolas como: alunos, professores nos supermercados, circos e principalmente centralizados em diversos bairros e centros das cidades, sendo assim vejo a importância de se conhecer a cultura suas diversidades, particularidades, ritualidades e religiosidades nos espaços que estão inseridos, também a importância de vermos os ciganos com cidadãos brasileiros e não como uma religião.

Em relação a segunda pergunta ao perguntar: Como se dá a sua relação com os membros ciganos que moram em sua comunidade? Eliana, afirma que o convívio com os ciganos e principalmente com a mulher cigana são pacíficas, fácil convívio, os mesmos zelam pela sua cultura, respeitam os de dentro e os de fora 
da cultura, extraindo só o que é pertinente para sua sobrevivência e evolução em meio à sociedade.

Para a confirmação interétnica entre ciganos e não ciganos trazemos o relato de Souza (2017, p.60) informa que em sua pesquisa observou um bom convívio entre ciganos e não ciganos. De tal modo, percebe-se que pode haver sim proximidades com os ciganos sem conflito, mas vale ressaltar que, o respeito a sua cultura e distanciamento do lar cigano, ainda continua sendo fundamental para manter viva sua cultura. Entretanto, para poder circular em um ambiente da cultura cigana a autorização é essencial e vale pontuar que só o líder autoriza a entrada.

\section{Considerações Finais}

É necessário compreendermos de fato como se dão as práticas das tradições da mulher cigana e as construções das identidades no cenário em meio a realidade em que vivem, assim sendo os trânsitos e fluxos entre o seu universo cultural e aquele encontrado se dão de forma contínua, com influências e imbricações diversas.

A aproximação dos evangélicos, sobretudo dos neopentecostais com os ciganos se dá em um contexto no qual essa matriz religiosa está nas periferias sociais e geográficas das cidades, onde também estão os ciganos. Os trânsitos e as estratégias de sobrevivências acabam por aproximar o cotidiano desses grupos, onde então se dá as relações e trânsitos interétnicos.

É difícil imaginar que as músicas, os vestuários e as referências do sagrado no espaço da igreja neopentecostal não dialoguem com referências também da cultura cigana. Essa aproximação nos mostra como é necessário pensar que se há um "núcleo duro", residual, porém irredutível, parafraseando Manuela Cunha (2009), nas culturas evangélicas e cigana, há outras zonas que são negociáveis, fluídas e intercambiáveis, quando estes dois universos se encontram nas periferias das cidades.

REFERÊNCIAS 
Universidade Federal rio Grande-FURG -Licenciatura em Educação do Campo. Ênfase em ciências da Natureza e Ciencia Agraria- LEdoc.

BARTH, F. Grupos étnicos e suas fronteiras. The social organization of culture difference. Bergen, Oslo: Universitteraforlaget, 1969. In: BARTH, F.; POUTIGNAT, P.; STREIFF-FERNART, J. Teorias da etnicidade: seguido de grupos étnicos e suas fronteiras de Fredrik Barth. Trad. Elcio Fernandes. 2. ed. São Paulo: Ed. Unesp, 2011, p. 187-227.

BORBA, Ângela Meyer. O brincar como um modo de ser e estar no mundo. In: BRASIL, Ministério da Educação. Secretaria de Educação Básica. Ensino Fundamental de nove anos: Orientações para a inclusão de crianças de seis anos de idade. 2. ed. Brasília, 2007, p. 33-45.

BERGER, P. L.; LUCKMANN, T. A construção social da realidade: tratado de sociologia do conhecimento. 23. ed. Petrópolis: Vozes, 2003

CASTELLS, M. O poder da identidade. 6. ed. São Paulo: Paz e Terra, 2008. Publicado originalmente em 1942.

COUTINHO. Cassi Ladi Reis. Os ciganos nos registros policiais mineiros (1907- 1920). Tese apresentada ao Programa de Pós-Graduação em História da Universidade de Brasília (UnB), 2016.

COSTA Elisa Lopes (2001), O Povo cigano - memória histórica, presente e futura. Que sorte ciganos na nossa escola! Colecção Interface, Centre de recherches tsiganes, Secretariado Entreculturas, Lisboa: ME 15-31.

CUNHA, Manuela Carneiro da. Cultura com aspas e outros ensaios; São Paulo: Cosac \& Naiy, 2009.

DECLARAÇÃO UNIVERSAL DOS DIREITOS HUMANOS Considerando que a Terceira Conferência Interamericana Extraordinária (Buenos Aires, 1967... Artigo 18. Direito

Entrevista concedida a Brigitte Grossmann Cairus. Curitiba/Indaial, 04 de setembro de 2018. Entrevista

FRIEDMANN, A (2012). O brincar na Educação Infantil: observação, adequação e inclusão. São Paulo: Moderna

GEERTZ, C. A interpretação das culturas. Rio de Janeiro: LTC, 1989

GEERTZ, Clifford. Uma Descrição Densa: Por Uma Teoria Interpretativa da cultura. In: A Interpretação das culturas. Rio de Janeiro: Zahar, 2008. P. 3-21.

GUIMARÃIS, Marcos Toyansk Silva. O associativismo transnacional cigano: identidade, diásporas e territórios. 2012. 231 f. Tese (Doutorado em Geografia) Faculdade de Filosofia, Letras e Ciências Humanas, Universidade de São Paulo, 2012. 
GIDDENS, Anthony. Sociologia. Lisboa: Fundação Calouste Gulbenkian, $6^{a} e d$ ano 2008

GOMES, A. M. A (2011). Um estudo sobre a conversão religiosa no protestantismo histórico e na psicologia social da religião. Ciências da Religião - História e Sociedade, 9(2), p. 148-174.

HALL, Stuart. A identidade cultural na pós-modernidade.Trad.de Tomaz Tadeu da Silva e Guacira Lopes Louro.1 1. ed. Rio de Janeiro: DP\&A, 2006

HILKNER, Regiane Aparecida Rossi. Ciganos, peregrinos do tempo: ritual, cultura e tradição. Tese (Doutorado) - Instituto de Artes - Universidade Estadual de Campinas, Campinas, 2008.

LAGO, Elma Cerqueira Barretto. As relações étnicas entre os ciganos e demais habitantes da cidade de maracás no espaço escolar. Dissertação de Mestrado. PPGREC, Jequié, 2020

LUCENA, Thatiany Deodato de. SANTOS, Raíssa Castro Camilo dos; AMORIM, Andrea de Lima Trigueiro. Alma cigana: a história de um povo, a cultura e a vida em comunidade. INTESA, Recife Universidade Católica de Pernambuco, Recife, 2016.

MOTA, Maria Lúcia Rodrigues (Re) Conhecer a Cultura Cigana: Uma Proposta de Inclusão ao Currículo Escolar em Trindade-GO [manuscrito] / Maria Lúcia Rodrigues MOTA. - 2015

MOONEN, Frans. Anticiganismo: os ciganos na Europa e no Brasil. $3^{a}$. ed. Digital, revista e atualizada. Recife:201 1

Monteiro, E. N. J., \& Goldfarb, M. P. L. (2017). A infância Calon: Notas sobre o "ser criança" entre os ciganos no Vale do Mamanguape - Paraíba/Brasil. Fragmentos de Cultura, 27(1), 19-29. https://doi.org/10.18224/frag.v27i1.5445

MONTEIRO, Gilson. A metalinguagem das roupas. Biblioteca On-line de Ciências da Comunicação, ISSN: 1646-3137. São Paulo. p.167-181,1999. Disponível em: http://bocc.ubi.pt/pag/monteiro-gilson-roupas.pdf

MIRCEA, ELIADE. Imagens e Símbolos. Lisboa: Arcádia, 1979.

PERIPOLLI, Gláucia Casagrande. As raízes das flores: Uma etnografia entre mulheres ciganas em Pelotas, RS. Dissertação (Mestrado em Ciências Sociais) - Instituto de Sociologia e Ciência Política. Programa de Pós- 105 Graduação em Ciências Sociais. Universidade Federal de Pelotas, 2013.

PERPÉTUO, Lenilda Damasceno. Comunidade cigana Calon em processo de escolarização: conflitos e saberes pluriculturais. Dissertação (Mestrado em Educação) - Faculdade de Educação, Universidade de Brasília, Brasília, 2017. 
RAMANUSH, N. Atrás do muro invisível: crença, tradição e ativismo cigano. $1^{\circ}$ ed. São Paulo:Editora Bandeirantes, 2012.

SOUZA, Marisa Lisboa de. Atualização e Manutenção da Identidade Étnica: etnografia sobre o processo de conversão religiosa de ciganos em Cruz das Almas/BA. Dissertação 181 (Mestrado em Ciências Sociais) - Programa de PósGraduação em Ciências Sociais, Universidade Federal do Recôncavo da Bahia, Bahia, 2017

SHIMURA, Igor. Ser cigano: identidade étnica em um acampamento calon itinerante. Maringá: Amazon, 2017

STANESCON, Mirian (2007). Lilá Romai. Cartas ciganas: o verdadeiro oráculo cigano. São Paulo: Smart vídeos editora.

VENTURA, M. C. S. P. A Experiência da Criança Cigana no Jardim de Infância. Universidade do Minho: Braga, 2004

KISHIMOTO, T. M. (2002). O brincar e suas teorias São Paulo: Pioneira-Thomson Learning. 